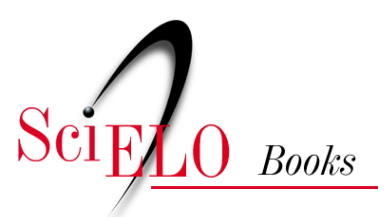

\title{
15 Tribo Moquinieae H. Rob.
}

\author{
Helen A. Ogasawara \\ Nádia Roque
}

OGASAWARA, H.A., and ROQUE, N. Tribo Moquinieae H. Rob.. In: ROQUE, N. TELES, A.M., and NAKAJIMA, J.N., comp. A família Asteraceae no Brasil: classificação e diversidade [online]. Salvador: EDUFBA, 2017, pp. 119-121. ISBN: 978-85-232-1999-4.

https://doi.org/10.7476/9788523219994.0017.

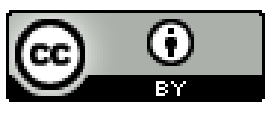

All the contents of this work, except where otherwise noted, is licensed under a Creative Commons Attribution 4.0 International license.

Todo o conteúdo deste trabalho, exceto quando houver ressalva, é publicado sob a licença Creative Commons Atribição $\underline{4.0}$. 


\section{TRIBO MOQUINIEAE H. ROB.}

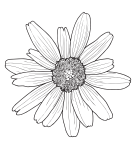

Helen A. Ogasawara

Nádia Roque

Robinson (1994) reestabeleceu Moquinia DC., anteriormente pertencente à tribo Mutisieae (CABRERA, 1969), e Pseudostifftia H. Rob., gênero descrito em Vernonieae (ROBINSON, 1979, 1980), situando-os em uma nova tribo, Moquinieae. Recentemente, os estudos de filogenia molecular e caracteres morfológicos (ramos do estilete curtos, espessos e papilosos na região abaixo do ponto de bifurcação e grãos de pólen com superfície equinada com espinhos longos) confirmaram a posição da tribo Moquinieae próxima, porém separada, de Vernonieae (ROBINSON, 2007, 2009). Na atual classificação, a tribo Moquinieae, juntamente a Arctoideae, Cichorieae, Eremonthamneae, Liabeae, Platycarpheae e Vernonieae, compõe a subfamília Cichorioideae (FUNK et al., 2009).

\section{Descrição}

Arbustos ou arvoretas, monoicos ou ginodioicos (Moquinia). Folhas simples, alternas, lâmina foliar com ápice arredondado a retuso, margem inteira, base cuneada, tomentosa, lepidota, tricomas glandulares sésseis, curto-pecioladas. Capitulescência piramidalmente tirsoide, ramos racemiformes, espiciformes ou corimbiformes, terminal; receptáculo epaleáceo. Capítulos discoides, homógamos, curto-pedunculados ou sésseis, cilíndricos, brácteas involucrais em 4-5 séries, graduadas, internas decíduas. Flores 1-5, corola actinomorfa, rósea, alva ou lilás, tubo da corola hipocraterifor- 
me, com tricomas glandulares externamente, 5 lobos, lineares; anteras calcaradas, curto-caudadas, apêndice do conectivo da antera 3-4 vezes tão longo quanto largo, estames abortados nas flores funcionalmente femininas; estilete curtamente bilobado, ápice arredondado a obtuso, espessado e escabroso abaixo da bifurcação (Figura 9F), estilopódio presente. Cipselas cilíndricas, 10-17-costadas, estrigosas, carpopódio anuliforme; pápus com cerca de 2 séries, cerdas 20-90, simples, série externa irregularmente mais curta, alvo ou ocre.

Moquinieae está representada por 2 gêneros, Moquinia e Pseudostifftia, ambos monoespecíficos (ROBINSON, 2009) e de distribuição restrita ao Brasil. As 2 espécies, M. racemosa (Spreng.) DC. (Figura 14A) e P. kingii H. Rob. (Figuras 14B-C), estão distribuídas nos estados da Bahia e Minas Gerais, principalmente na Cadeia do Espinhaço, em áreas de cerrado, nas fitofisionomias de campos gerais e campos rupestres.

\section{Chave de identificação para os gêneros de Moquinieae no Brasil}

1. Lâmina foliar alvo-tomentosa na face abaxial, discolor, ramos cinéreos; capitulescência dupla racemiforme ou espiciforme, flores 3-5, corola rósea a alva, pápus ocre. Moquinia

1'. Lâmina foliar glabra, concolor, ramos castanhos, ferrugíneos; capitulescência paniculiforme, flor 1, corola lilás, pápus alvo Pseudostifftia

\section{Literatura recomendada}

CABRERA, A. L. El genero Moquinia (Compositae). Boletin de la Sociedad Argentina de Botanica, La Plata, v. 11, p. 255-264, 1969.

CANDOLLE, A. P. de. Prodromus Systematis Naturalis Regni Vegetabilis. Paris: Treuttel \& Würtz, 1838. v. 7. 
FUNK, V. et al. Compositae metatrees: the next generation. In: FUNK, V. A. et al. (Ed.). Systematics, Evolution and Biogeography of Compositae. Vienna: IAPT, 2009. Chapt. 44, p. 749-765.

GAMERRO, J. C. Identidad de Pseudostifftia con Moquinia (Compositae) y consideraciones sobre la ubicación tribal del taxon. Darwiniana, Buenos Aires, v. 30, n. 1-4, p. 123-136, 1990.

ROBINSON, H. Moquinieae. In: KADEREIT, J. W.; JEFFREY, C. (Ed.). Families and Genera of Vascular Plants: v. VIII: Flowering Plants. Eudicots. Asterales. Berlin Springer-Verlag, 2007. p. 148-149

ROBINSON, H. Moquinieae. In: FUNK, V. A. et al. (Ed.). Systematics, Evolution and Biogeography of Compositae. Vienna: IAPT, 2009. Chapt. 30, p. 477-481.

ROBINSON, H. Notes on the tribes Eremothamneae, Gundelieae and Moquinieae, with comparisons of their pollen. Taxon, Utrecht, v. 43, n. 1, p. 33-44, 1994.

ROBINSON, H. Two new genera of Vernonieae (Asteraceae) from Brazil, Heterocypsela and Pseudostifftia. Phytologia, Huntsville, v. 44, p. 442-450, 1979.

ROBINSON, H.; BOHLMANN, F.; KING, R. M. Chemosystematic notes on the Asteraceae. III. Natural subdivisions of the Vernonieae. Phytologia, Huntsville, v. 46, p. 421-436, 1980. 